\title{
LFA-1 expression by blood eosinophils is increased in atopic asthmatic children and is involved in eosinophil locomotion
}

\author{
S. Lantero*, G. Alessandri+, D. Spallarossa*, L. Scarso**, G.A. Rossi*
}

LFA-1 expression by blood eosinophils is increased in atopic asthmatic children and is involved in eosinophil locomotion. S. Lantero, G. Alessandri, D. Spallarossa, L. Scarso, G.A. Rossi. CERS Journals Ltd 1998.

ABSTRACT: Allergic asthma is characterized by eosinophil migration in the airways, which is strictly dependent on the expression of adhession molecules. This study investigated whether the expression of adhesion molecules on eosinophils is increased and associated with disease activity in allergic asthma.

Twenty atopic asthmatic (AA) subjects and nine controls were studied and the expression of lymphocyte function-associated antigen-1 (LFA-1; CD11a/CD18), Mac1 (CD11b/CD18) and very late antigen-4 (VLA-4; CD49d/CD29) on blood eosinophils was evaluated by specific monoclonal antibody (Mab) staining and flow-cytometric analysis.

Compared with controls, eosinophils from AA showed increased expression of LFA-1 (p<0.005), but not of Mac-1 or VLA-4 (p>0.1). In addition, LFA-1 expression correlated positively with blood eosinophil number $(r=0.792, p<0.05)$, while no correlations were observed between Mac-1 or VLA-4 expression and blood eosinophil number. The migration of eosinophils through human umbilical vein endothelial cells with or without anti-LFA-1, Mac-1 and VLA-4-blocking Mab was studied. Compared with controls, eosinophils from AA showed increased migration toward C5a $(p<0.01)$. Cell migration was totally inhibited by preincubating eosinophils with anti-LFA-1 $(p<0.05)$, while anti-Mac-1 had no effect $(p>0.1)$.

Thus, the expression of lymphocyte function-associated antigen-1 by blood eosinophils is increased in atopic asthmatics and seems to modulate the enhanced eosinophil migration observed in allergic asthma.

Eur Respir J 1998; 12: 1094-1098.
*Pulmonary Division, **Transfusional Centre, G. Gaslini Institute, Genoa, Italy, ${ }^{+}$Department of Cell Biology, IST, Genoa, Italy.

Correspondence: S. Lantero

Pulmonary Division

G. Gaslini Institute

Largo G

Gaslini 516147

Genoa

Italy

Fax: 39103776590

Keywords: Adhesion molecules allergic asthma

cell migration

eosinophils

Recieved: December 21997

Accepted after revision July 21998

Supported by grant "Ricerca Finalizzata" no. ICS 34.1/RF 93.48 from the Ministero della Sanith, Rome, Italy.
In allergic asthma, inhalation of sensitizing allergens leads to eosinophil activation and recruitment [1]. The demonstration that eosinophils are toxic to human lung tissues [2] and that their presence in the airway mucosa is associated with morphological damage to the bronchial epithelium [3] has strongly supported the hypothesis that these cells could be involved as major effector elements in the pathogenesis of allergic asthma [4]. Eosinophil recruitment at the sites of allergic reaction is a complex mechanism, which includes the expression of surface adhesion molecules by circulating cells, which are able to interact with the counter-receptors expressed by vascular endothelial cells [5].

There is evidence that different adhesion molecules may mediate the different steps that characterize circulating cell transendothelial migration. In this context, eosinophils express a number of adhesion molecules, including lymphocyte function-associated antigen-1 (LFA-1 or CD11a/ CD18), Mac-1 (CD11b/CD18) and very late antigen-4 (VLA-4 or CD49d/CD29) [5]. VLA-4 and its endothelial cell receptor, vascular cell adhesion molecule-1 (VCAM-1) appear to be involved in the initial adherence of activated eosinophils [6], when the cells slow down in the bloodstream, "rolling" along the endothelial wall, while LFA-1, Mac-1 and their receptor, intercellular adhe- sion molecule-1 (ICAM- 1), are important for eosinophil extravasation [7]. With this background, the present study was designed to evaluate the intensity of LFA-1, Mac-1 and VLA-4 expression on blood eosinophils isolated from children with allergic as-thma. The functional relevance of these different molecules in modulating in vitro eosinophil migration through an endothelial cell layer was also tested.

\section{Materials and methods}

\section{Reagents}

The reagents used in the study were as follows. Complete medium comprised RPMI-1640 (PAA, Linz, Austria), $50 \mathrm{U} \cdot \mathrm{mL}^{-1}$ penicillin, $50 \mathrm{mg} \cdot \mathrm{mL}^{-1}$ streptomycin, $2 \mathrm{mM} \mathrm{L}$ glutamine, $2 \mathrm{mg} \cdot \mathrm{mL}^{-1} \mathrm{NaHCO}_{3}, 1 \times$ nonessential amino acids, $5 \%$ foetal calf serum (FCS; Flow ICN, Irvine, UK), and $2 \mathrm{mM}$ 2-mercaptoethanol (Sigma Chemical Co., St Louis, MO, USA). Endothelial basal medium (EBM) was from Difco Laboratories (Milan, Italy), trypan blue and phosphate-buffered saline (PBS) from Flow ICN, and Dextran 70,000 Da, 10× Hank's balanced salt solution (HBSS), sodium azide $\left(\mathrm{NaN}_{3}\right)$ and complement factor 5a (C5a) 
from Sigma. Heparin was from Parke-Davis, (Lainate, Milan, Italy), Percoll from Pharmacia (Uppsala, Sweden) and Diff Quick from Merz\&Dade (Dudingen, Switzerland). Mouse immunoglobulin ( $\mathrm{Ig}) \mathrm{G}_{1}$ monoclonal antibody (Mab) ahCD11a conjugated to R-phycoerythrin (PE) and unconjugated (clone B-B15), mouse $\mathrm{IgG}_{1} \mathrm{CD} 3 / \mathrm{PE}$ and unconjugated, as isotype control, ahCD11b/PE and unconjugated, ahCD49d/PE and unconjugated were from Serotec (Oxford, UK), while mouse (Ig)G $\mathrm{G}_{1}$ Mab ahCD16b conjugated to fluoroscein isothiocyanate (FITC) was from Ortho Diagnostic System (Milan, Italy).

\section{Population}

Eosinophils were obtained from nine nonatopic control subjects (6-11 yrs old, seven males and four females) and 20 atopic asthmatic (AA) children (5-14 yrs old, 15 males and 5 females), sensitized to house dust mites, demonstrated by a skin prick test and radioallergosorbent test (RAST) (Pharmacia, Uppsala, Sweden) (table 1). Asthma was defined according to the criteria of the American Thoracic Society [8]; all patients were able to perform a forced expiratory manoeuvre and had a clinical history of reversible airway obstruction, characterized by a $>15 \%$ increase in forced expiratory volume in one second (FEV1) after inhalation of $200 \mu \mathrm{g}$ salbutamol and/or a positive inhalation challenge with methacholine. Neither control nor AA subjects had suffered from respiratory infections in the previous 4 weeks and none were on any treatment other than $\beta_{2}$-agonists on an as-necessary basis. The study was approved by the G. Gaslini Institute Ethical Committee and parents or guardians of all subjects gave their informed consent.

\section{Eosinophil purification}

Isolation of blood eosinophils was performed on discontinuous Percoll gradients, as described previously [9].
In brief, to $10 \mathrm{~mL}$ of heparinized blood, an equal amount of $6 \%$ dextran in $0.9 \% \mathrm{NaCl}$ was added, mixed gently and incubated at $37^{\circ} \mathrm{C}$. After $30-40 \mathrm{~min}$ the upper phase was collected, washed once in PBS, resuspended in $1.5 \mathrm{~mL}$ of $1.070 \mathrm{~g} \cdot \mathrm{mL}^{-1}$ Percoll with $5 \%$ FCS and layered on a discontinuous Percoll gradient with the following volumes and densities $\left(\mathrm{g} \cdot \mathrm{mL}^{-1}\right)$ respectively: $1.5,1.100 ; 3,1.090 ; 3$, 1.085; and 3, 1.080 [9]. The Percoll gradient densities were obtained by mixing nine parts Percoll with one part $10 \times$ HBSS $(90 \%$ Percoll) and then diluting the $90 \%$ Percoll solution with $1 \times$ HBSS with $5 \%$ FCS. The normodense eosinophils recovered between 1.090 and $1.095 \mathrm{~g}$. $\mathrm{mL}^{-1}$ Percoll were washed twice in PBS and resuspended at $10^{6}$ eosinophils $\cdot \mathrm{mL}^{-1}$ in complete medium. Recovered eosinophils were $70-80 \%$ pure, as established by DiffQuick staining, with neutrophils as a contaminant, and $96 \%$ viability, as determined by the trypan blue dye exclusion test.

Evaluation of adhesion molecule expression on eosinophils

The expression of LFA-1 (CD11a/CD18), Mac-1 (CD11b/ CD18) and VLA-4 (CD49d/CD29) on eosinophils from nine control and 20 AA subjects was evaluated by staining with specific Mabs and flow cytometry. Cells were washed once in PBS, resuspended in $100 \mu \mathrm{L} \mathrm{PBS}+2 \% \mathrm{FCS}+$ $0.5 \mu \mathrm{g} \cdot \mathrm{mL}^{-1} \mathrm{NaN}_{3}$ (staining medium) and stained with 10 $\mu \mathrm{g} \cdot \mathrm{mL}^{-1}$ of ahCD16b/FITC (green fluorescence) to distinguish by two-colour flow cytometry the contaminating neutrophils, CD16b+, from the eosinophils, CD16b- [10] and $10 \mu \mathrm{g} \cdot \mathrm{mL}^{-1}$ of Mabs ahCD11a, ahCD11b, ahCD49d or ahCD3 (as mouse IgG isotype control), all PE-conjugated (red fluorescence). To test the possibility that the process of eosinophil separation could increase the expression of some membrane receptors detected by flow cytometry, as suggested by a recent paper [11], whole-blood staining

Table 1. - Characteristics of the atopic asthmatic subjects included in the study

\begin{tabular}{|c|c|c|c|c|c|c|c|c|c|}
\hline \multirow[b]{2}{*}{$\begin{array}{l}\text { Subject } \\
\text { No. }\end{array}$} & \multirow[b]{2}{*}{ Sex } & \multirow[b]{2}{*}{$\begin{array}{l}\text { Age } \\
\text { yrs }\end{array}$} & \multirow[b]{2}{*}{ Sensitivity } & \multirow[b]{2}{*}{$\begin{array}{c}\text { WBC } \\
\text { cells } \cdot \mathrm{mm}^{-3}\end{array}$} & \multicolumn{5}{|c|}{ Blood cell number $\mathrm{n}$} \\
\hline & & & & & $\mathrm{N}$ & $\mathrm{L}$ & $\mathrm{E}$ & B & Mo \\
\hline 1 & $\mathrm{M}$ & 5 & HP & 10,740 & 8100 & 1200 & 500 & 100 & 600 \\
\hline 2 & $\mathrm{M}$ & 11 & $\mathrm{H}$ & 8020 & 4300 & 2700 & 500 & 100 & 400 \\
\hline 3 & $\mathrm{M}$ & 5 & HGB & 8940 & 5400 & 3700 & 400 & 100 & 700 \\
\hline 4 & M & 5 & $\mathrm{H}$ & 7000 & 3200 & 2900 & 300 & 0 & 400 \\
\hline 5 & $\mathrm{~F}$ & 5 & $\mathrm{H}$ & 10,000 & 6400 & 2200 & 600 & 100 & 500 \\
\hline 6 & M & 7 & $\mathrm{H}$ & 7740 & 1600 & 4600 & 600 & 100 & 400 \\
\hline 7 & $\mathrm{~F}$ & 6 & HG & 5960 & 2800 & 2000 & 600 & 100 & 300 \\
\hline 8 & $\mathrm{M}$ & 5 & HP & 8320 & 2400 & 4600 & 500 & 100 & 400 \\
\hline 9 & M & 8 & HPGOD & 5250 & 2200 & 2200 & 300 & 100 & 300 \\
\hline 10 & M & 5 & $\mathrm{H}$ & 9320 & 4200 & 3000 & 1400 & 100 & 400 \\
\hline 11 & M & 5 & HD & 11,540 & 4300 & 4900 & 1300 & 100 & 600 \\
\hline 12 & $\mathrm{M}$ & 14 & HG & 6640 & 2800 & 1900 & 1300 & 100 & 500 \\
\hline 13 & $\mathrm{M}$ & 9 & HPGD & 7210 & 3200 & 3000 & 300 & 0 & 500 \\
\hline 14 & $\mathrm{~F}$ & 12 & HG & 4610 & 2100 & 1900 & 300 & 0 & 200 \\
\hline 15 & $\mathrm{M}$ & 8 & HGO & 6860 & 2800 & 2600 & 900 & 100 & 400 \\
\hline 16 & M & 12 & HPD & 5890 & 3700 & 1200 & 400 & 0 & 400 \\
\hline 17 & M & 6 & $\mathrm{H}$ & 8550 & 4000 & 2700 & 1000 & 100 & 600 \\
\hline 18 & $\mathrm{~F}$ & 12 & $\mathrm{H}$ & 8060 & 6100 & 1300 & 200 & 0 & 400 \\
\hline 19 & $\mathrm{~F}$ & 5 & $\mathrm{H}$ & 11,660 & 6300 & 3500 & 700 & 100 & 600 \\
\hline 20 & M & 5 & HP & 14,110 & 8500 & 3600 & 600 & 100 & 800 \\
\hline
\end{tabular}

WBC: white blood cells; N: neutrophils; L: lymphocytes; E: eosinophils; B: basophils; Mo: monocytes; M: male; F: female; H: house dust mites; P: parietaria; G: gramineae; O: oleaceae; D: animal dander. 
was also performed in five AA and three control subjects. The cells were then incubated for $1 \mathrm{~h}$ at $4^{\circ} \mathrm{C}$, washed twice in staining medium and resuspended at $5 \times 10^{5}$ cells. $\mathrm{mL}^{-1}$ in $200 \mu \mathrm{L}$ of PBS. The red fluorescence intensity by CD16b-cells (eosinophils) was read on 10,000 acquired cells with the flow cytometry instrument FACScan (Becton Dickinson, Milan, Italy) and expressed as mean fluorescence channel (MFC). To compare the fluorescence intensity of different samples, the cells were acquired at identical settings of the logarithmic amplifier and analysed with Lysis II software (Becton Dickinson). After conversion to linear fluorescence intensity units, to obtain a linear function of fluorescence intensity over a wide range, the average background obtained with the control antibody, the ahCD3/PE Mab, was subtracted from the average fluorescence intensity of the specifically stained cells [12].

\section{Evaluation of eosinophil migration through endothelial cell layer}

Eosinophils from five control and 10 AA subjects (from whom enough cells were recovered to perform the assay) were employed to evaluate cell locomotion through human umbilical vein endothelial cells (HUVEC). The day before the assay, $5 \times 10^{5}$ HUVEC were seeded on polycarbonate membranes with 5 - $\mu \mathrm{m}$ pores coated with collagen type I, in order to reach confluence on the next day, and incubated at $37^{\circ} \mathrm{C}, 5 \% \mathrm{CO}_{2}$, in EBM [13]. On the day of the assay the membranes were placed in Boyden chemotaxis chambers with the HUVEC side-up. The lower wells were filled with $50 \mu \mathrm{L}$ of complete medium, to evaluate the random migration, or with $\mathrm{C} 5 \mathrm{a}\left(0.1 \mu \mathrm{g} \cdot \mathrm{mL}^{-1}\right)$ in complete medium, as an eosinophil chemoattractant [14]. Eosinophils were preincubated with or without Mabs ahCD11a, ahCD11b, ahCD49d or mouse IgG, as an isotype control $\left(10 \mu \mathrm{g} \cdot \mathrm{mL}^{-1}\right)$ for $30 \mathrm{~min}$ at $37^{\circ} \mathrm{C}, 5 \% \mathrm{CO}_{2}$ before the chemotaxis assay. Then, $100 \mu \mathrm{L}$ of $10^{6}$ eosinophil. $\mathrm{mL}^{-1}$ were seeded on the upper chamber compartments, on the HUVEC side. After $3 \mathrm{~h}$ of incubation at $37^{\circ} \mathrm{C}, 5 \% \mathrm{CO}_{2}$, the membranes were detached, HUVEC peeled off the upper side and the eosinophils that had migrated across the HUVEC to the lower side were fixed, stained with DiffQuick and counted under a light microscope. All chemotactic conditions were tested in duplicate and the data were expressed as the number of migrated eosinophils in 10 high power fields $(\mathrm{HPF}$; magnification $\times 400)$ [14].

\section{Statistical analysis}

Data are expressed as mean \pm SEM. Statistical comparisons between different culture conditions of cells from the same donor group were made by paired t-test, (parametric data) or Mann-Whitney test (nonparametric data), while comparisons between the same culture conditions of cells from different donor groups were made by the Student's t-test [14]. Differences were considered significant when $\mathrm{p}<0.05$.

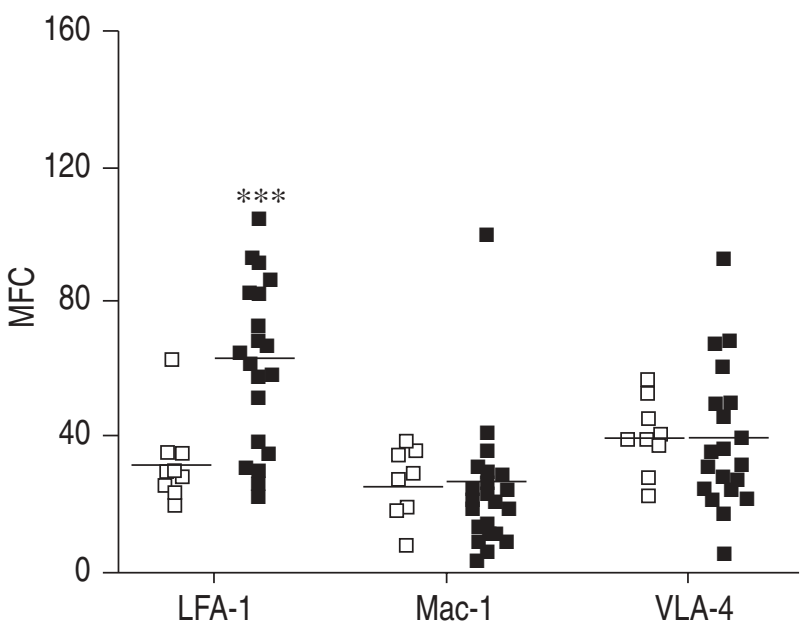

Fig. 1. - Expression of lymphocyte function-associated antigen-1 (LFA-1), Mac-1 and very late antigen-4 (VLA-4) by circulating eosinophils from control subjects $(\square)$ and atopic asthmatic children (ם). The expression intensity is indicated as mean fluorescence channel (MFC). Mean shown by horizontal lines. $* * *: \mathrm{p}<0.001$, significant difference between groups.

\section{Results}

Constitutive adhesion molecule expression by blood eosinophils

Specific Mabs identified the presence of LFA-1, Mac-1 and VLA-4 molecules on all eosinophils recovered from venous blood of AA and control subjects, while no staining was observed with the mouse IgG isotype control, ahCD3 Mab (not shown). The intensity of LFA-1 expression was significantly higher on eosinophils from the 20 AA than on those from the nine control subjects $(62 \pm 5$ and $33 \pm 6$ MFC, respectively; $p<0.001$ ), while there were no significant differences in Mac-1 or VLA-1 expression ( $\mathrm{p}>$ 0.1 ) (fig. 1). The levels of LFA-1 expression in the AA subjects were widely distributed; therefore, the AA subjects were divided into two subgroups: the first group with LFA-1 expression similar to control values (low LFA-1 expressors) and the second group with LFA-1 expression higher than the mean of the control plus 2 SD (high LFA-1 expressors). Compared with the controls or the low expressors, the high expressors showed an increased asthma score $(\mathrm{p}<0.001$ and $\mathrm{p}<0.05$, respectively), higher eosinophil number $(\mathrm{p}<0.001$ and $\mathrm{p}<0.05$, respectively) and

Table 2. - Expression of lymphocyte function-associated antigen-1 (LFA-1)

\begin{tabular}{lrcccc}
\hline Subjects & \multicolumn{1}{c}{$\mathrm{n}$} & AS & LFA-1 MFC & E cells $\mathrm{mm}^{-3}$ & RAST \\
\hline Control & 9 & 0 & $33 \pm 6$ & $56 \pm 13$ & 0 \\
AA low & 6 & $0.7 \pm 0.2$ & $32 \pm 2$ & $400 \pm 68$ & $41 \pm 15$ \\
AA high & 14 & $1.4 \pm 0.2$ & $75 \pm 4$ & $736 \pm 101$ & $76 \pm 8$
\end{tabular}

Values are mean \pm SEM. AS: asthma score; MFC: mean fluorescence channel; E: eosinophils; RAST: radioallergosorbent test; AA low: low LFA-1 expressing asthmatic children; AA high: high LFA-1 expressing asthmatic children. 
greater allergen-specific IgE serum levels $(\mathrm{p}<0.001$ and $\mathrm{p}<0.05$, respectively) (table 2 ). The process of eosinophil separ-ation did not modify adhesion molecule expression in either AA or control subjects, since no differences in LFA-1, Mac-1 and VLA-4 levels were found when evaluating eosinophils in unseperated whole-blood samples or after discontinuous Percoll gradient seperation (not shown).

\section{Eosinophil migration through human umbilical vein endo- thelial cells}

Eosinophils from AA subjects showed a higher migration rate than those from control subjects $(\mathrm{p}<0.05)$ (fig. $2 a)$. The increased migration of eosinophils in AA subjects was possibly related to LFA-1 expression, since the enhanced chemotactic activity was inhibited back to spontaneous migration levels by preincubation of the cells with ahCD11a Mabs (19 \pm 3 versus $6 \pm 2$ eosinophils 10 HPF-1, $\mathrm{p}=0.001)$. Interestingly, preincubation with ahCD49d downregulated cell migration only partially $19 \pm 3$ versus $13 \pm 2$ eosinophils-10 $\mathrm{HPF}^{-1},(\mathrm{p}<0.05)$, while no inhibition was seen with ahCD11 Mabs (p<0.1) (fig. 2b).

\section{Discussion}

Quantifying the expression of adhesion molecules on blood eosinophils in children with allergic asthma, a significantly increased expression of LFA-1, but not of Mac-1 or VLA-4 was demonstrated. Moreover, the high LFA-1 expressors showed more severe asthma (as judged by the asthma score), higher eosinophil number and higher levels of allergen-specific IgE. This increased LFA-1 expression seemed to be functionally relevant since eosinophils from AA subjects showed increased locomotion through HUVEC which was completely blocked by Mab ahCD11a.

Eosinophils can be activated by both immune and nonimmune mechanisms to synthesize and/or release biological mediators, including toxic granule proteins, free oxy- gen radicals, eicosanoids, leukotrienes, platelet activating factor, cytokines and growth factors [15]. Because of these various activities, recruitment of eosinophils from the bloodstream is regarded as a key event in the allergic inflammation. Indeed, several studies have demonstrated that the number of eosinophils and the levels of eosinophil-derived proteins correlate with the severity of asthma [16], and that their presence in the bronchial mucosa is associated with morphological damage to the bronchial epithelium [4].

The bronchial inflammation that characterizes asthma is modulated and maintained by mediators released by airway parenchymal and inflammatory cells [6, 17, 18]. Some of these mediators, such as interleukin (IL)-3, IL-5, granulocyte-macrophage colony-stimulating factor (GM-CSF) and eotaxin have the potential to activate eosinophils and enhance their locomotion and survival [5, 10, 19, 20]. Chronic exposure to these pro-inflammatory cytokines may result in a preactivation state of circulating cells [21, 22], which includes an increased ability to migrate through endothelial cell layers, as demonstrated in the asthmatic children in the present study.

The observation that LFA-1 is expressed more on eosinophils isolated from AA than from control subjects is consistent with the concept that pre-activation of circulating polymorphonuclear leukocytes is present in allergic asthma [17] and with the demonstration that a rapid and massive migration of these cells into target tissue occurs during acute asthma attacks [22]. In addition, the demonstration that LFA-1 expression on circlating eosinophils is increased in mild atopic asthmatics with higher asthma score and allergen-specific IgE in serum, further supports the hypothesis of a significant link between circulating eosinophil activation and the activity and/or severity of the asthma [17].

These data indicate that VLA-4 appears to be less impotant than LFA-1 in allowing eosinophil migration through the endothelium. Indeed, VLA-4 appears to be a determinant in the initial adherence to the vessel wall, allowing the cells to slow down in the bloodstream [6] (a condition not mimicked in the present in vitro assay), while LFA-1
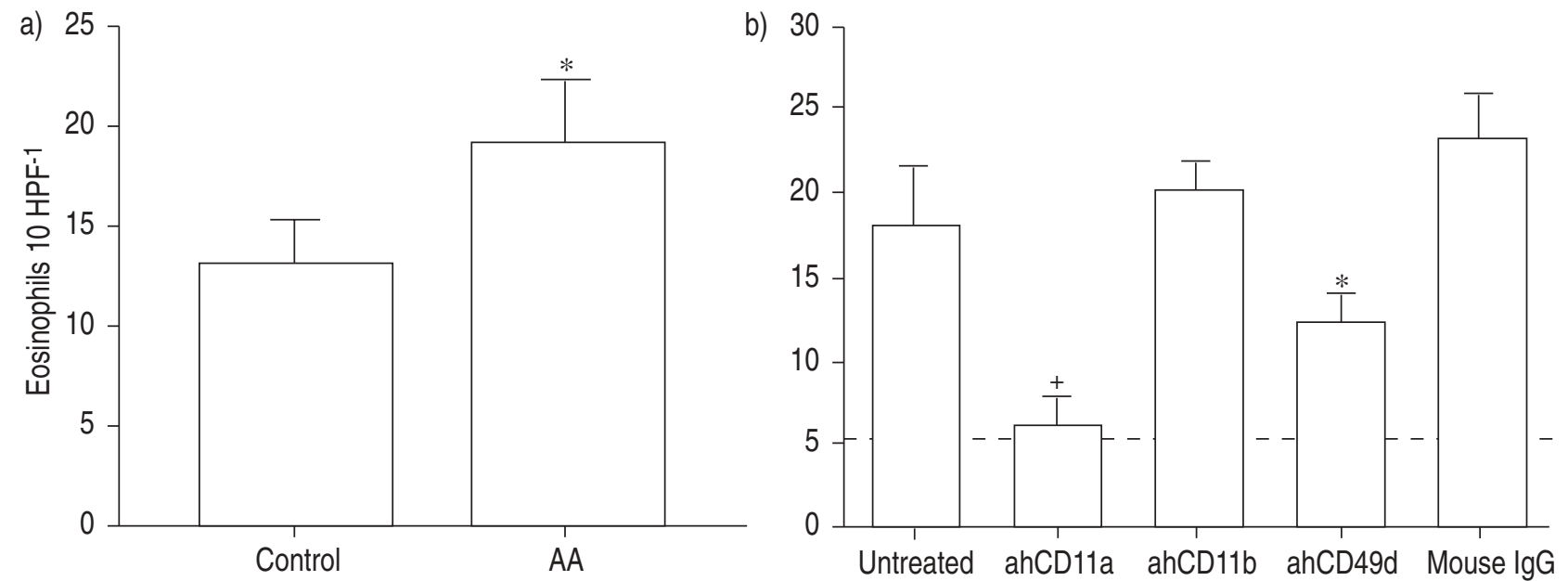

Fig. 2. - Migration of eosinophils from atopic asthmatic (AA) children through human umbilical vein endothelial cells (HUVEC) towards complement factor 5a (C5a) $0.1 \mu \mathrm{g} \cdot \mathrm{mL}^{-1}$. The number of eosinophils that migrated in $10 \mathrm{high}$ power fields (HPF) is shown. a) eosinophils from control and subjects; b) eosinophils from AA unstimulated or stimulated with ahCD23 and preincubated with ahCD11a, ahCD11b, ahCD49d monoclonal antibodies or mouse immunoglobulin $(\mathrm{Ig}) \mathrm{G}$. The broken line represents the random migration. *: $\mathrm{p}<0.05 ;{ }^{+}: \mathrm{p}<0.005$. 
is involved mainly in the migration through the endothelium [7] (a condition reproduced by the present experimental system).

It was also oberved that Mac-1 expression is not increased on blood eosinophils from young allergic asthmatic subjects and that it is not efficient in mediating eosinophil transendothelial migration. Since it has been demonstrated that in asthmatic patients Mac-1 (and not LFA-1) expression is increased on bronchial eosinophils, compared with blood eosinophils from the same subjects [23], it is possible that Mac-1 could be involved in processes that follow transendothelial migration, such as the interaction with other airway cells in the tissues.

The first step in cell migration is represented by the adhesion of circulating cells to vascular endothelial cells. Adhesion mechanisms can be upregulated not only through increased surface molecule expression but also through conversion of the adhesion molecules from a low to very high avidity state [6]. It has been demonstrated that IL-3, IL-5 and GM-CSF increase adhesion receptor avidity [24]. Since these qualitative changes occur within a very short time (minutes) and do not last for long [6, 24], they are likely to be more important in rapid cell-to-cell interactions e.g. between immunoeffector cells, rather than in a process that requires a longer interaction such as the crossing of the endothelial barriers.

In summary, lymphocyte function-associated antigen-1 is overexpressed on blood eosinophils from allergic asthmatic children and it is involved, as a major adhesion molecule, in the migration of eosinophils through the endothelium.

\section{References}

1. Smith DL, Deshazo RD. Bronchoalveolar lavage in asthma. Am Rev Respir Dis 1993; 148: 523-532.

2. Davis WB, Fells GA, Sun XH, Gadek JE, Venet A, Crystal RG. Eosinophil-mediated injury to lung parenchymal cells and interstitial matrix: a possible role for eosinophils in chronic inflammatory disorders of the lower respiratory tract. J Clin Invest 1984; 74: 296-308.

3. Ohashi Y, Motojima S, Fukuda T, Makino S. Airways hyperresponsiveness, increased intercellular space of bronchial epithelium and increased infiltration of eosinophils and lymphocytes in bronchial mucosa in asthma. Am Rev Respir Dis 1992; 145: 1469-1478.

4. Berman JS, Weller PF. Airway eosinophils and lymphocytes in asthma: birds or feather? Am Rev Respir Dis 1992; 145: 1246-1248.

5. Resnick MB, Weller PF. Mechanisms of eosinophil recruitment. Am J Respir Cell Mol Biol 1993; 8: 349-355.

6. Johnson FL, Haraldsen G, Aanesen JP, Haye R, Brandtzaeg P. Eosinophil infiltration is related to increased expression of vascular cell adhesion molecule-1 in nasal polyps. Am J Respir Cell Mol Biol 1995; 12: 624-632.

7. Bloemen PJM, Buckley TL, van der Tweel MC. LFA-1, and not Mac-1, is crucial for the development of hyperreactivity in a murine model of nonallergic asthma. Am J Respir Crit Care Med 1996; 153: 521-529.

8. American Thoracic Society. Definition and classification of chronic bronchitis, asthma and emphysema. Am Rev Respir Dis 1962; 85: 762-768.
9. Gartner I. Separation of human eosinophils in density gradients of polyvinylpyrrolidone-coated silica gel (Percoll). Immunology 1980; 40: 133-136.

10. Hartnell A, Moqbel R, Walsh CM, Bradley B, Kay AB. Fcg and CD11/CD18 receptor expression on normal density and low density human eosinophil. Immunology 1990; 69: 264-270.

11. Mawhorter SD, Stephany DA, Ottesen EA, Nutman TB. Identification of surface molecules associated with physiologic activation of eosinophils: application of whole blood flow cytometry to eosinophils. J Immunol 1996; 156: 4851-4858.

12. Spurzem JR, Sacco O, Rossi GA, Beckman JD, Rennard SI. Regulation of MHC class II gene expression on bovine bronchial epithelial cells. J Lab Clin Med 1992; 120: 94-102.

13. Gimbrone MA Jr, Cotran RS, Folkman J. Human vascular endothelial cells in culture. J Cell Biol 1974; 6: 673684.

14. Lantero S, Sacco O, Scala C, Morelli MC, Rossi GA. Eosinophil locomotion and the release of IL-3 and IL-5 by allergen-stimulated mononuclear cells are effectively downregulated in vitro by budesonide. Clin Exp Allergy 1996; 26: 656-664.

15. Spray CJF, Kay AB, Gleich GJ. Eosinophils 1992. Iтmиnol Today 1992; 13: 384-388.

16. Brusasco V, Crimi E, Gianiorio P, Lantero S, Rossi GA. Allergen-induced increase in airway responsiveness and inflammation in mild asthma. J Appl Physiol 1990; 69: 2209- 2214.

17. Shult PA, Lega M, Jadidi S, et al. The presence of hypodense eosinophils and diminished chemiluminescence response in asthma. J Allergy Clin Immunol 1988; 81: 429-437.

18. Pilewsky JM, Albelda SM. Cell adhesion molecules in asthma: homing, activation and airway remodelling. Am J Respir Cell Mol Biol 1995; 12: 1-3.

19. Das AM, Flower RJ, Peretti M. Eotaxin-induced eosinophil migration in the peritoneal cavity of ovalbumin-sensitized mice. J Immunol 1997; 159; 1466-1473.

20. Shemi R, Wardlaw AJ, Cromwell O, Kurihara K, Waltmann P, Kay AB. Interleukin-5 selectively enhances the chemotactic response of eosinophils obtained from normal but not eosinophilic subjects. Blood 1992; 79: 2952 2959.

21. Warringa RAJ, Koendermann L, Kok PTM, Kreukniet J, Bruijinzel PBL. Modulation and induction of eosinophils chemotaxis by granulocyte-macrophage colony-stimulating factor and interleukin-2. Blood 1991; 77: 2694-2700.

22. Spallarossa D, Sacco O, Girosi D, Rossi GA. Blood eosinophil counts and arterial oxygen tension in acute asthma. Arch Dis Child 1995; 73: 333-337.

23. Mengelers HJ, Maikoe T, Brinkman L, Hooibrink B, Lammers JW, Koendermann L. Immunophenotyping of eosinophils recovered from blood and BAL of allergic asthmatics. Am J Respir Crit Care Med 1994; 149: 345351.

24. Bloom M, Tool ATJ, Kok PTM, Koenderman L, Roos D, Verhoeven AJ. Granulocyte-macrophage colony-stimulating-factor, interleukin-3 (IL-3) and IL-5 greatly enhance the interaction of human eosinophils with opsonized particles by changing the affinity of complement receptor type 3. Blood 1994; 83: 2978-2984. 